\title{
Interactions between local winds and coastal sea surface temperatures near the Canterbury coast
}

\section{IAN G. McKENDRY ${ }^{1}$}

ANDREW P. STURMAN ${ }^{2}$

IAN F. OWENS ${ }^{2}$

${ }^{1}$ Department of Geography

University of British Columbia

Vancouver, Canada

${ }^{2}$ Department of Geography

University of Canterbury

Christchurch, New Zealand

\begin{abstract}
A modelling and observational study was conducted in 1982-83 into the relationships between airflow and sea surface temperature along the Canterbury coast near Banks Peninsula. Nearshore sea surface temperatures dropped by as much as 3-4 ${ }^{\circ} \mathrm{C}$ during periods of strong offshore airflow, particularly north-westerlies. This may have been associated with coastal upwelling. A following southerly may also have contributed to this temperature drop by moving colder water from the south. The colder water appeared to produce enhanced sea breezes owing to the resulting increased temperature difference between land and sea. Both modelling and empirical evidence is given to support this. Coastal upwelling of cold water appeared to produce decreased air temperatures near the coast, although the onshore airflow warmed up as it moved inland over warmer surfaces.
\end{abstract}

Keywords sea surface temperature; sea breezes; local winds; Canterbury; air-sea interaction; coastal upwelling

\section{INTRODUCTION}

The role of differences in surface temperatures of adjacent land and sea masses in developing local winds in coastal areas has long been appreciated (see Atkinson 1981 for a review). In some instances, it has been shown that interaction between coastal winds and the ocean can lead to upwelling of colder water, thereby increasing land-sea temperature differentials and strengthening onshore winds (Hawkins \& Stuart 1980). For example, coastal upwelling off Oregon, U.S.A., has been shown to cause decreases in sea surface temperature (SST) of $8^{\circ} \mathrm{C}$ within a matter of days (Holladay \& O'Brien 1975). Modelling studies by Clancy et al. (1979) suggest that coastal upwelling leads to a shallower, sharper, faster, and longer lasting sea breeze front that penetrates further inland.

In New Zealand, most recent studies of SSTs have concentrated on spatial distributions and the influence of such factors as currents, mixing, surface heating, and upwelling on these patterns (Kibblewhite et al. 1982; Bowman et al. 1983; Barnes 1985). This reflects, at least to some extent, recent improvements in use of satellite imagery for determining SST (Kidson \& Taylor 1984; Taylor \& Kidson 1985). Some studies have, however, examined the temporal variation of SSTs in coastal areas. For example, Heath (1970) suggested that over $24 \mathrm{~h}$ a $5{ }^{\circ} \mathrm{C}$ decrease in SSTs near Kaikoura could be attributed to increased advective transport of the northward flowing Southland Current during strong southerly airflows. Heath (1972a) also examined periods of warmer SSTs near Kaikoura which were thought to arise from warm eddies breaking off the East Cape Current System. The role of northerly winds in coastal upwelling along the north Canterbury coast was also examined by Heath (1972b). He showed good agreement between upwelling calculated from wind records using the Ekman formula and that calculated from changes in isotherm and isohaline positions over a 6-day period.

This paper examines two periods of significantly depressed SSTs near Banks Peninsula which occurred during a more general study of local airflow over the Canterbury Plains (McKendry 1985). These periods are investigated by applying the Colorado State University mesoscale numerical model 


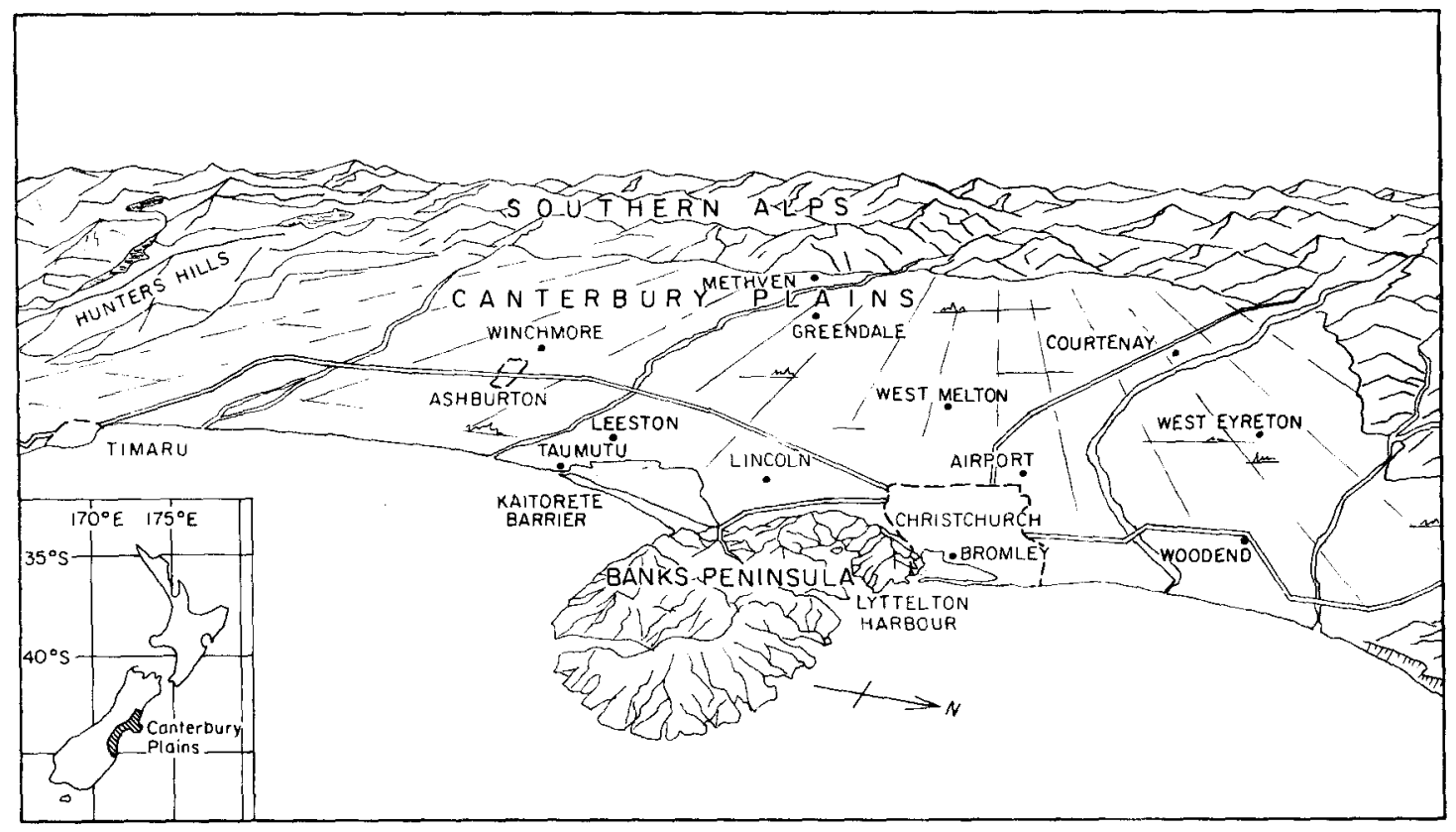

Fig. 1 Oblique view of the Canterbury region illustrating major topographic features and the location of places mentioned in the text (modified from Sturman \& Tyson 1981).

(Pielke 1974; Mahrer \& Pielke 1975, 1976, 1977, 1978 ) to varying land-sea thermal contrasts at initialisation.

\section{METHODS}

The data used in the present study were collected from January 1982 to August 1983. SST was measured on a daily basis at the entrance to Lyttelton Harbour (Fig. 1) by pilot launch. These data were collected on behalf of the New Zealand Oceanographic Institute, Wellington, and represent the most consistent and reliable record of SST for the region. Basic meteorological data were kindly provided by the New Zealand Meteorological Service (synoptic charts, hourly wind data, thermograph data), whereas hourly windspeed and direction, and screen level temperature data were obtained from instruments installed to augment the observational network for the period of the local wind study. These include an anemograph at Leeston (south of Banks Peninsula) and thermographs at both Bromley and Courtenay (north of Banks Peninsula, Fig. 1).

The CSU mesoscale model as presented in its original form by Pielke (1974) was a three-dimensional airflow model developed primarily for the simulation of land-sea breezes in the vicinity of the south Florida peninsula. Subsequently the model has been generalised and used widely for a number of applications including investigation of airflow over mountains, mountain-valley winds, and air pollution dispersion. The model is described in detail by McKendry (1985).

To realistically simulate thermal forcing in the Canterbury region it was found necessary to modify the way in which surface temperatures over land and sea were specified in the model. Formerly, SST was equated with land temperature at model initialisation. However, this is unrealistic in the Canterbury context where SST is invariably warmer than the land at this time. In order to achieve an initial thermal contrast, a procedure suggested by McCumber et al. (1978) was adopted whereby the water surface is slowly heated incrementally during the first hour of dynamic initialisation (a procedure in which the model is run without heating of the land surface until steady state is reached). The twodimensional version of the model was used to evaluate this revision to the code. Analysis of the sensitivity of the model to varying initial land-sea temperature differentials provides an estimate of the likely influence of a significant decrease in SST on thermally forced wind systems in the region.

Simulations used 21 grid points in the horizontal direction (perpendicular to the coast) of which 10 were over sea. Twelve vertical levels were used ris- 


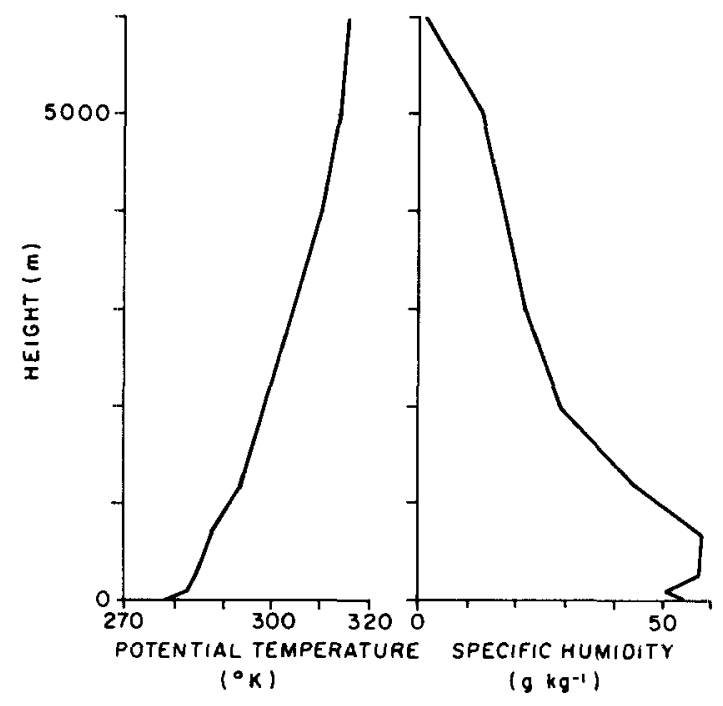

Fig. 2 Initial profiles of potential temperature and specific humidity (from $0700 \mathrm{~h}$ radiosonde sounding at Christchurch Airport, 27 January 1983).

ing to $6000 \mathrm{~m}$. Horizontal grid spacing was a constant $10 \mathrm{~km}$. A 60 -s time step was used with a 4$\mathrm{h}$ (simulated time) period of dynamic initialisation. The model was run without terrain and represents a flat plain with adjacent ocean. The synoptic wind was set to $3 \mathrm{~m} \mathrm{~s}^{-1}$ in an offshore direction. The remainder of the input data were representative of a summer day on the Canterbury Plains and were derived from a case study on 27 January 1983 (Table 1 and Fig. 2).

In the sensitivity analysis, the initial land-sea temperature differential (SST-land temperature) was varied through a range $0-14^{\circ} \mathrm{C}$ and the effect on the resultant airflow evaluated.

Table 1 Initial values of model input parameters.

\begin{tabular}{|c|c|c|}
\hline Albedo & 0.2 & \\
\hline Initial roughness length & 0.04 & $\mathbf{m}$ \\
\hline Roughness length land & 0.04 & $\mathrm{~m}$ \\
\hline Smoother coefficient $Z$ & 0.0 & \\
\hline Smoother coefficient $Y$ & 0.07 & \\
\hline Lapse rate & 4.0 & ${ }^{\circ} \mathrm{C} \mathrm{km}^{-1}$ \\
\hline Surface pressure & 1019 & mbar \\
\hline Soil conductivity & 1.26 & $\mathrm{~W} \mathrm{~m}^{-1}{ }^{\circ} \mathrm{C}^{-1}$ \\
\hline Soil density & 1500 & $\mathrm{~kg} \mathrm{~m}^{-3}$ \\
\hline Soil specific heat & 1340 & $\mathrm{~J} \mathrm{~kg}^{-1}{ }^{\circ} \mathrm{C}^{-1}$ \\
\hline Soil wetness & 50 & $\mathrm{~kg} \mathrm{~m}^{-3}$ \\
\hline $\begin{array}{l}\text { Initial height of planetary } \\
\text { boundary layer }\end{array}$ & 400 & $\mathrm{~m}$ \\
\hline
\end{tabular}

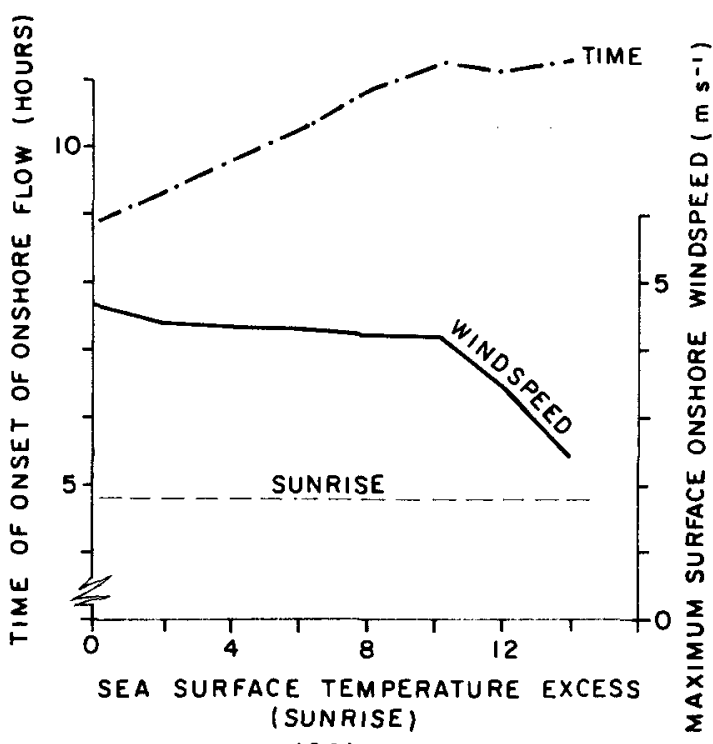

Fig. 3 Sensitivity of airflow model to initial land-sea temperature contrasts. Time of initial development of onshore flow and maximum onshore windspeed by SST excess are given.

\section{RESULTS}

In Fig. 3 the effect of cooling SST from initial values between 0 and $14{ }^{\circ} \mathrm{C}$ warmer than land temperature to equality with land temperature at the initial time is shown. The most dramatic effect is on the time of sea breeze onset with onshore flow beginning up to $2.5 \mathrm{~h}$ earlier with no land-sea temperature contrast at the initial time. This is to be expected in view of the reduced amount of surface heating required to produce a sufficient land-sea thermal contrast to initiate an onshore wind. Surface windspeeds $(5 \mathrm{~m})$ show little sensitivity to land-sea temperature contrasts although for SST excesses greater than $10^{\circ} \mathrm{C}$ there is a marked decrease in surface windspeeds. It is likely that this decrease is an indication that a cut-off point is being approached. This cut-off will occur when the horizontal thermal gradient is insufficient for sea breeze development.

The nature of horizontal and vertical changes in the sea breeze circulation induced by varying the initial land-sea thermal contrast is shown in Fig. 4. The range of sunrise SSTs between 0 and $14^{\circ} \mathrm{C}$ is examined to assess the sensitivity of subsequent airflow to a wide range of temperature differentials. Taking the two extremes, comparison of the onshore (negative $u$ ) velocity components for midafternoon reveals that the sea breeze circulation developed under conditions of no initial land-sea 
A

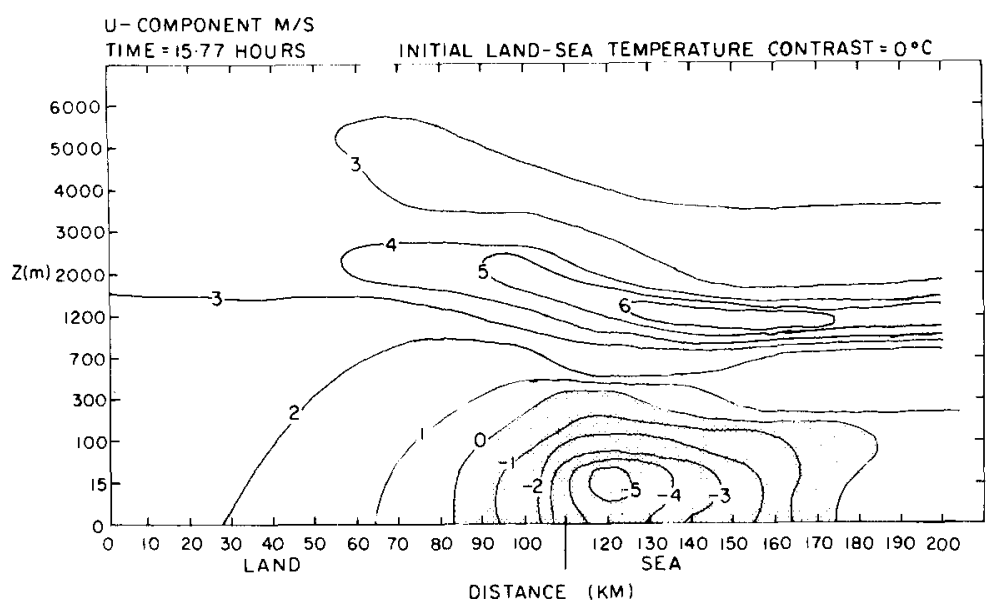

B



Fig. 4 Prediction of onshore velocity components for twodimensional transect, summer, $15.79 \mathrm{~h}$ for sunrise SST excess of $A, 0^{\circ} \mathrm{C}$ and $\mathrm{B}, 14^{\circ} \mathrm{C}$. (Times are given in decimal fractions of an hour.) temperature contrast is much stronger than that developed with a SST excess at sunrise of $14^{\circ} \mathrm{C}$. Not only does the circulation associated with cooler SSTs penetrate further inland, the onshore velocities are virtually doubled in the layer up to $100 \mathrm{~m}$. The results presented in Fig. 3 and 4 suggest that in the Canterbury region a reduction of SST during a coastal upwelling episode of the order of $5^{\circ} \mathrm{C}$ (e.g., a sunrise SST excess of $2^{\circ}$ instead of $7^{\circ}$ ) could be expected to result in earlier sea breeze onset and stronger onshore winds above the surface, as well as extension further inland.

\section{SST fluctuations and associated meteorological conditions}

SSTs showed marked fluctuations during the study period both on a seasonal and daily basis (Fig. 5).
Conspicuous features of the SST record were the two large reductions in SST $\left(3-4^{\circ} \mathrm{C}\right)$ at the beginning of January 1982 and late November/early December 1982. Comparison of the SST record at Lyttelton Harbour with that at Timaru $(150 \mathrm{~km}$ to the south-west) for the same period confirms that these episodes were widespread (and not due to measurement error).

The meteorological conditions associated with each episode suggest that both occurred in situations likely to induce significant coastal upwelling (Fig. 6). In the January episode a $3.7^{\circ} \mathrm{C}$ decrease in SST coincided with a period from 4 January $(0400 \mathrm{~h})$ to 6 January $(0600 \mathrm{~h})$ when strong northwesterly winds predominated at the coastal sites. At Christchurch Airport, the maximum hourly average windspeed over this period was $14.3 \mathrm{~m} \mathrm{~s}^{-1}$ with $8 \mathrm{~h}$ having hourly average speeds of at least 


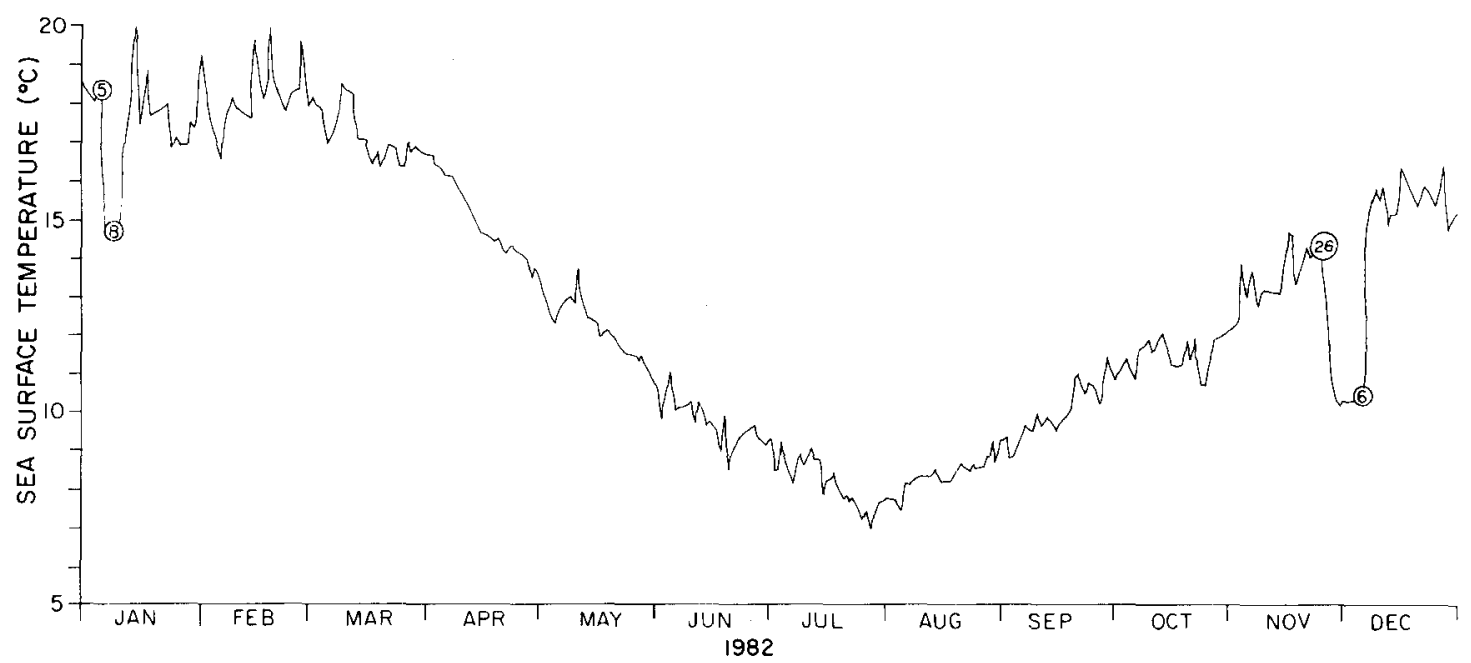

Fig. 5 Daily sea surface temperatures, Lyttelton Harbour 1982 (circled values represent critical dates).

$10 \mathrm{~m} \mathrm{~s}^{-1}$. This was followed by a period of cool south-westerlies which continued until early on 9 January $(0400 \mathrm{~h})$. The following few days exhibited a strong diurnal temperature cycle with the dominance of locally-developed airflow. Figure 6A indicates that although the weather maps showed southwesterly gradient flow, the observed winds at Bromley had a diurnal variation with onshore airflow (particularly in the afternoon). During this period the SST gradually rose to above its original level. A similar pattern is evident in the November/December episode when a SST decline of $4.2^{\circ} \mathrm{C}$ occurred between 26 and 29 November (Fig. 6B). SSTs remained below normal until 7 December. At Bromley, surface north-westerlies began on 25 November $(0900 \mathrm{~h})$ and continued until 28 November $(1420 \mathrm{~h})$. Over this period the maximum hourly average windspeed at Christchurch Airport was $14.3 \mathrm{~m} \mathrm{~s}^{-1}$ while hourly average speeds during $20 \mathrm{~h}$ were at least $10 \mathrm{~m} \mathrm{~s}^{-1}$. These north-westerlies were again followed by surface south-westerlies until 1 December $(1700 \mathrm{~h})$. The airflow from 1 December became more variable than in the January episode, largely because of rapid changes in the synoptic weather pattern. The weather maps in Fig. 6B show that a second, but less distinct, southerly change occurred between 2 and 3 December followed by weak north-westerly airflow. Consequently, although there is some evidence of afternoon sea breeze development (e.g., 1, 3 , 6, and 7 December), the lee trough developed onshore flow, discussed by Sturman \& Tyson (1981) and McKendry (1985), also seemed to occur on 2 and 4 December.
Both episodes appear to be consistent with a sustained period of coastal upwelling induced by strong offshore winds. However, without measurements of ocean currents in the coastal zone it is impossible to provide conclusive proof of this relationship. It may also be conjectured that the tendency for strong post-frontal southerlies to follow northwesterly events increases advective transport of the cool northward flowing Southland Current which may act to reinforce the effects of this inferred coastal upwelling.

\section{Effect on local winds}

An important feature of the Canterbury Plains wind regime is the shallow localised south-easterly sea breeze which forms along the coastline to the southwest of Banks Peninsula. This sea breeze is frequently embedded in the predominant low level north-easterly which flows into the trough formed in the lee of the Alps (McKendry 1985). At Leeston the sea breeze produces a distinctive anemograph signature which is characterised by an abrupt swing from north-easterly winds to south-easterly winds in mid-morning with an abrupt return to the northeast in late afternoon (Fig. 7A). Over the study period 77 such events were observed. As shown in Fig. 7B the majority of these events occurred during late summer with earliest onsets also occurring at this time. This may be attributed to the increased day length and solar radiation inputs in summer. The time of sea breeze cessation showed less seasonal variability owing to the tendency for the lee trough north-easterly to strengthen in late afternoon and obliterate the sea breeze prematurely. 
A
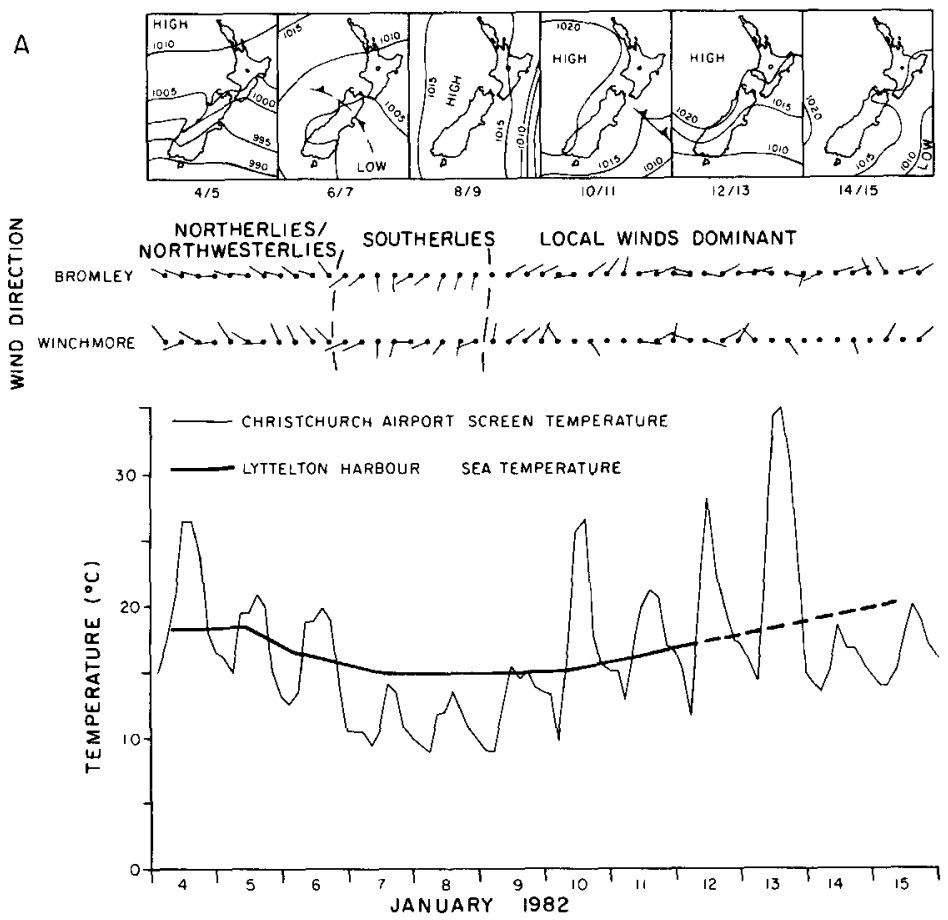

$\mathrm{B}$

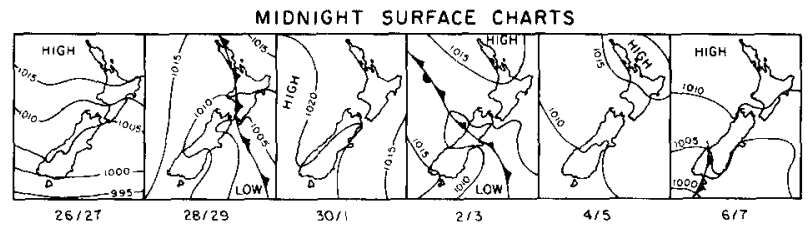

NORTHERLIES SOUTHERLIES LOCAL WINOS DOMINANT
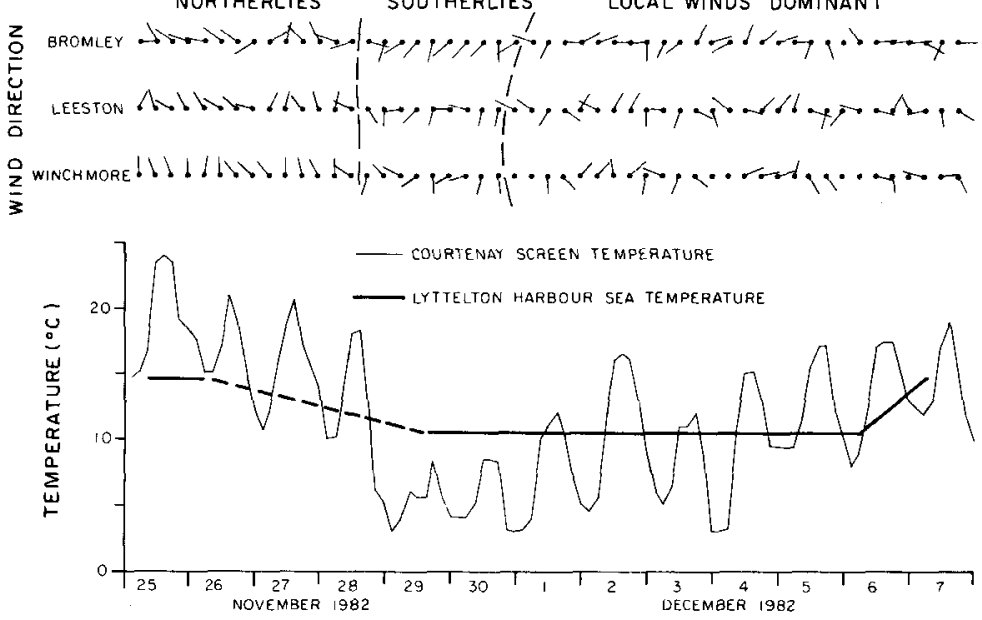

Fig. 6 Case study examples of coastal upwelling along the Canterbury coast. (For wind directions, north is towards the top of the page.) A, January 1982. B, November-December 1982. 
Fig. 7 A, Typical south-easterly sea breeze signature at Leeston. B, Mean monthly onset and cessation times and mean monthly frequency for south-easterly events embedded in north-easterly flow at Leeston (March 1982 - August 1983).

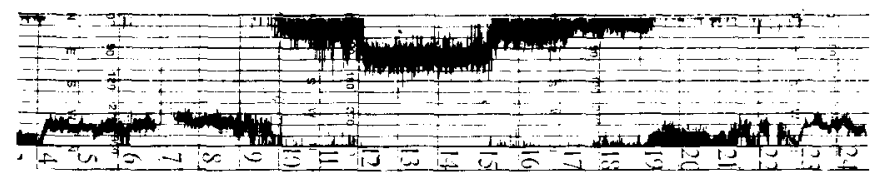

A



From Fig. 8 it is apparent that the onset of these events strongly depends on the land-sea thermal contrast measured in terms of the difference in screen temperature at Christchurch Airport and SST at Lyttelton Harbour. Numerous studies suggest that sea breeze development is dependent on this index. For example Brittain (1978), in forecasting sea breezes at Eskmeals (United Kingdom), noted that onshore winds set in only when the difference between screen temperature inland and nearshore SST was positive. The events were thus clearly associated with a positive land-sea temperature contrast.

One such sea breeze occurred on 6 December 1982 (Fig. 9), coinciding with the period of cool SSTs associated with the second episode. This sea breeze was conspicuous for its early onset (c. $0750 \mathrm{~h}), 1 \frac{1}{2} \mathrm{~h}$ earlier than the next earliest of the 77 occurrences. Despite the early onset on this occasion, the air temperature over land $\left(10.9^{\circ} \mathrm{C}\right)$ still exceeded the SST $\left(10.4^{\circ} \mathrm{C}\right)$ at onset owing to the unusually cool SSTs. Unfortunately, little can be deduced about the structure and intensity of the sea breeze since no vertical profiles were attempted on that day. It is also difficult to ascertain the effect of the cool SSTs on the thermal characteristics of the sea breeze since no thermographs were located in the localised coastal region in which the sea breeze occurred. However, it is known that SST influences the thermal characteristics of the northeasterly which prevails to the north of Banks Peninsula (McKendry 1985). A regression of air temperature $2 \mathrm{~h}$ after onset minus temperature at onset of the north-easterly at Bromley $\left(T_{2}-T_{B}\right)$, versus onset temperature minus SST $\left(\mathrm{T}_{\mathrm{B}}-\mathrm{SST}\right)$, revealed a correlation coefficient of -0.67 (significant at the $0.01 \%$ level and goodness of fit of 0.45 ), for those events initiated during daytime. The regression equation is given by:

$$
\left(T_{B}-S S T\right)=-1.01\left(T_{2}-T_{B}\right)+0.21
$$

This may be simplified to relate air temperature 2 $h$ after onset with SST as follows:

$\mathrm{T}_{2}=\mathrm{SST}+0.21$ 


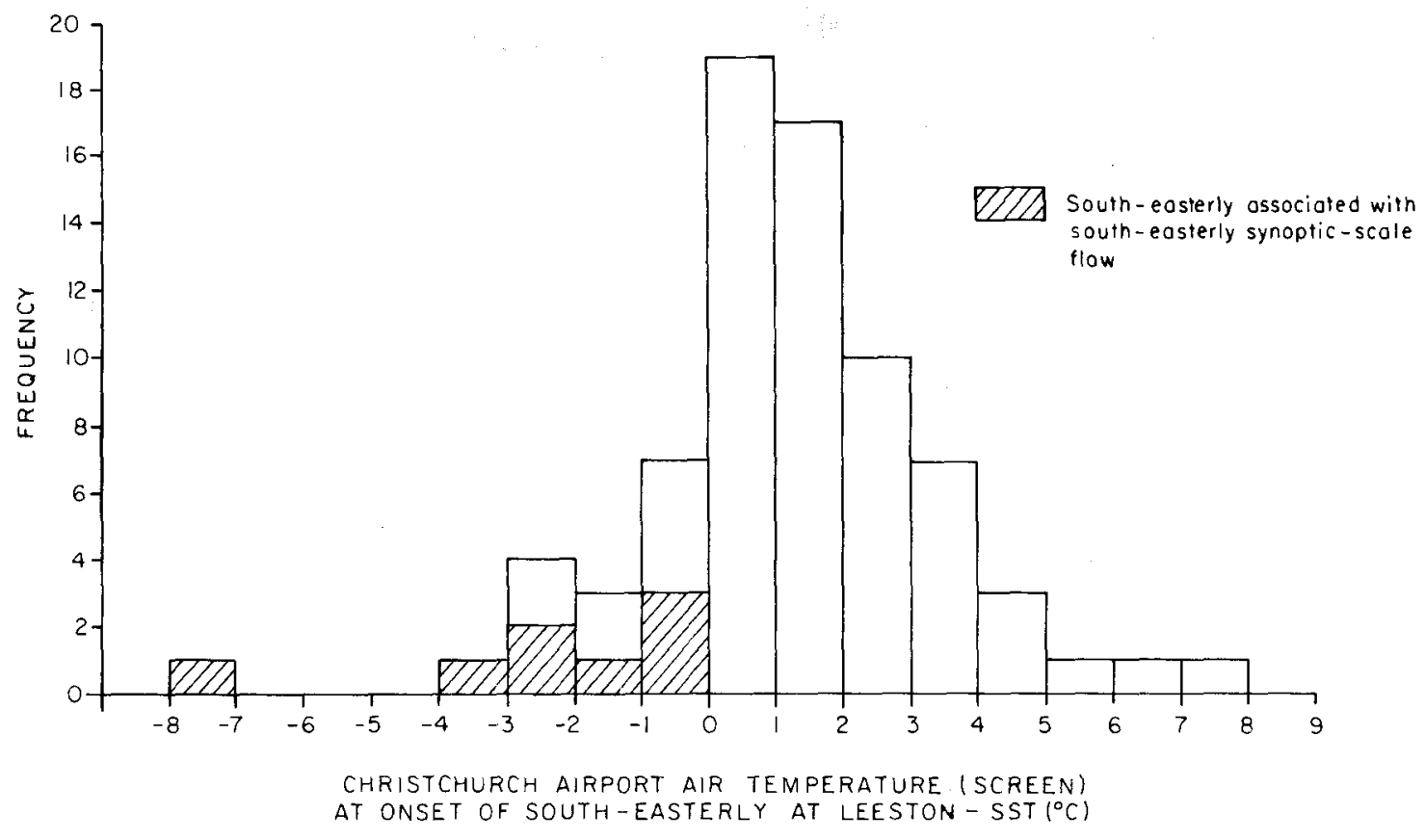

Fig. 8 Frequency of land-sea temperature differentials for south-easterlies embedded in north-easterlies at Leeston.

This tendency for air temperature to approximate SST following sea breeze onset was found to be a coastal phenomenon with temperatures inland tending to be relatively unaffected. It is likely that the effects of terrestrial heating and the associated enhanced mixing are responsible for warming of the marine air as it travels inland. These results suggest that unusually cool SSTs not only influence the timing and strength of the sea breeze but also lead to cooler coastal air temperatures.

\section{CONCLUSIONS}

Despite the incidental nature of the observations presented, this study provides a useful indication of the weather patterns associated with variations of nearshore SST in the Canterbury region and the effects of the resulting cool SSTs on the local wind regime.

Investigation of meteorological conditions associated with two episodes of markedly reduced sea surface temperature observed over an 18-month period suggest that upwelling may occur during sustained periods of north to north-westerly winds. Heath (1972b) identified upwelling further north along the east coast under more northerly winds. However, the coastline in the immediate vicinity of Christchurch has a more north-south orientation. Ekman (1905) showed that the net transport of surface water owing to surface wind stress is directed to the left in the southern hemisphere. Over open sea the deflection can vary between $30^{\circ}$ and $60^{\circ}$ (Stommel 1954) although the angle is reduced by frictional effects in shallow water (Ridgway 1972). Consequently, along the coastline of Pegasus Bay, offshore movement of surface water is most likely to occur during flow directions, particularly between north and west. The relatively infrequent nature of significant cool SST events may be attributed to the predominance of the low level northeasterly wind which flows into the trough formed in the lee of the mountains during gradient flow from a westerly quarter. Only in strong pressure gradients may the north-westerly penetrate across the plains and nearshore zone creating the necessary offshore movement of surface water to initiate coastal upwelling. The tendency for such events to be followed by strong cool south-westerly winds suggests that increased advective transport of the cool Southland Current as described by Heath (1970) may act to maintain or further reduce SSTs after a coastal upwelling episode.

A sensitivity analysis of the CSU mesoscale model to varying initial land-sea temperature contrasts provided a theoretical estimate of the effect of coastal upwelling on sea breeze development in 
Fig. 9 Leeston anemograph trace during an apparent upwelling event, 6 December 1982, showing early onset of south-easterly sea breeze.

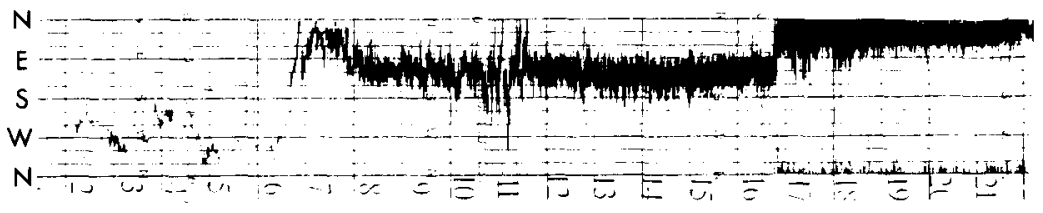

the Canterbury region. Results were in agreement with those of Clancy et al. (1979) and suggest that decreases in SST of the order observed in the Lyttelton data are sufficient to induce earlier, stronger, and longer lasting sea breezes. The early development of a local sea breeze on 6 December 1982 during a sea surface cooling episode provides empirical support for these predictions.

The observed tendency for coastal screen ternperatures to approximate SST during daytime north-easterly flow suggests that these cooling episodes are likely to influence the thermal characteristics of both the lee trough north-easterly and the south-easterly sea breeze. Unusually cool SSTs may therefore result in cooler temperatures near the coast although it is likely that terrestrial heating and mixing may remove these effects inland, particularly in summer. Suggestions that the northeasterly contains a significant sea breeze component (Trenberth 1977) would indicate that strength and temporal characteristics of the north-easterly may also be influenced by cool SST episodes.

Clearly, more detailed investigations of such episodes are required if the results of the present study are to be confirmed and a wider understanding of local ocean-atmosphere interactions gained. A necessary objective would be the correlation of short-term spatial variations in SST and wind in the nearshore zone with the spatial, temporal, thermal, and structural characteristics of the associated local, thermally induced wind systems.

\section{REFERENCES}

Atkinson, B. W. 1981: Meso-scale atmospheric circulations. Academic Press. 495 p.

Barnes, E. J. 1985: Eastern Cook Strait region circulation inferred from satellite-derived, sea-surface, temperature data. New Zealand journal of marine and freshwater research 19: 405-411.

Bowman, M. J.; Kibblewhite, A. C.; Chiswell, S. M.; Murtagh, R. A. 1983: Shelf fronts and tidal stirring in greater Cook Strait. Oceanologica acta $6: 119-129$.

Brittain, D. W. 1978: Forecasting sea breezes at Eskmeals. Meteorological magazine 107: 88-96.

Clancy, R. M.; Thompson, J. D.; Hurlburt, H. E.; Lee, J. D. 1979: A model of mesoscale air-sea interaction in a sea breeze-coastal upwelling regime. Monthly weather review 107: 1476-1505.
Ekman, V. W. 1905: On the influence of the earth's rotation on ocean currents. Arkiv för matematik, astronomi och fysik 11: 1-52.

Hawkins, J. D.; Stuart, D. W. 1980: Low level atmospheric changes over Oregon's coastal upwelling region. Monthly weather review 108: 1029-1040.

Heath, R. A. 1970: An occurrence of low water temperatures on the north Canterbury coast. New Zealand journal of marine and freshwater research $5: 223-$ 226.

1972a: Wind derived water motions off the East Coast of New Zealand. New Zealand journal of marine and freshwater research 6: 352-364.

1972b: Oceanic upwelling produced by northerly winds on the north Canterbury coast, New Zealand. New Zealand journal of marine and freshwater research $6: 343-351$.

Holladay, C. G.; O'Brien, J. J. 1975: Mesoscale variability of sea surface temperatures. Journal of physical oceanography $5: 761-772$.

Kibblewhite, A. C.; Berquist, P. R.; Foster, B. A.; Gregory, M. R.; Miller, M. C. 1982: Maui Development Environmental Study Report on Phase Two 1977-1981. University of Auckland. 174 p.

Kidson, J. W.; Taylor, B. F. 1984: Enhancement and display of meteorological satellite imagery. Weather and climate $4: 23-27$

McCumber, M. C.; Schuh, J. A.; McNider, R. T.; Pielke, R. A.; Mahrer, Y. 1978: The University of Virginia Mesoscale Model. UVA Report No. UVA ENV SCI-MESO-1978-1, October, Department of Environmental Sciences, Clark Hall, University of Virginia, Charlottesville.

McKendry, I. G. 1985: An empirical and numerical modelling analysis of a complex mesoscale windfield, Canterbury plains, New Zealand. Unpublished PhD thesis, Department of Geography, University of Canterbury.

Mahrer, Y.; Pielke, R. A. 1975: A numerical study of the airflow over mountains using the two-dimensional version of the University of Virginia mesoscale model. Journal of the atmospheric sciences 32 : 2144-2155.

1976: Numerical simulation of the air flow over Barbados. Monthly weather review 104: 1392-1402.

1977: The effects of topography on the sea and land breezes in a 2-D numerical model. Monthly weather review 105: 1151-1162.

1978: A test of an upstream spline interpolation technique for the advective terms in a numerical mesoscale model. Monthly weather review 106 : 818-830. 
Pielke, R. A. 1974: A three-dimensional numerical model of the sea-breezes over south Florida. Monthly weather review 102: 115-139.

Ridgway, N. M. 1972: Direction of drift of surface oil with wind and tide. New Zealand journal of marine and freshwater research $6: 178-184$.

Stommel, H. 1954: Serial observations of drift currents in the central North Atlantic ocean. Tellus $6: 203-$ 214.
Sturman, A. P.; Tyson, P. D. 1981: Sea breezes along the Canterbury coast in the vicinity of Christchurch, New Zealand. Journal of climatology 1 : 203-219.

Taylor, B. F.; Kidson, J. W. 1985: Sea surface temperatures from satellites. Wellington, New Zealand Meteorological Service Information Publication 9.

Trenberth, K. E. 1977: Surface atmospheric tides in New Zealand. New Zealand journal of science 20:339356. 